\title{
Applicability of the McNamara analysis in a sample of adult Black South Africans
}

SADJ March 2019, Vol. 74 No. 2 p87 - p92

J Wanjau', MI Khan², MPS Sethusa ${ }^{3}$

\section{SUMMARY}

\section{Introduction}

Cephalometric norms have been established for the McNamara analysis for different age, racial and ethnic groups.

\section{Aim}

To establish McNamara cephalometric norms for a sample of Black South African adults and to compare with Caucasian norms.

\section{Methods}

Thirty lateral cephalograms of a sample of eligible untreated Black adult subjects was retrieved from archives in the Department of Orthodontics at the Medunsa Oral Health Centre. They were traced and digitized using Dolphin Imaging $®$ computer software. The McNamara analysis was performed. The one sample $t$-test was performed to compare study values with McNamara norms. The two sample $t$-tests were used to determine statistical differences between the data for genders.

\section{Results}

The mean age of the study subjects was 24 years $(S D=3.9)$. Two-thirds of the linear measurements were significantly higher than the McNamara norms. The angular measurements of female subjects were significantly higher than McNamara's reference values.

As regards gender differences, almost two-thirds of male linear measurements were higher than females, and the differences were statistically significant in half of the measurements. In contrast, though all higher, female angular measurements showed no statistically significant differences.

\section{Author affiliations:}

1. J Wanjau: BDS (Nairobi), MDS (Medunsa), P G Dip (University of Limpopo) M Dent Orthodontics (Sefako Makgatho Health Sciences University), Part-time Specialist in the Department of Orthodontics, Sefako Makgatho Health Sciences University.

2. MI Khan: BDS cum laude (Medunsa), M Dent Orthodontics (University of Limpopo), Senior part-time specialist in the Department of Orthodontics. Sefako Makgatho Health Sciences University.

3. MPS Sethusa B: (Diag) Rad. BDS (Medunsa), PDD (Stellenbosch), $M$ Dent Orthodontics (University of Limpopo), $P$ G Dip (UCT), Head of Department of Orthodontics, Sefako Makgatho Health Sciences University.

Corresponding author: $\mathrm{J}$ Wanjau

Medunsa Campus, PO Box D28, Sefako Makgatho Health Sciences University 0204. Tel: +27 (0)12 5214854 Email: wanjaujackk@gmail.com Medunsa Research and Ethics Committee (MREC).

\section{Conclusion}

Gender and racial differences exist in cephalometric norms measured using the McNamara analysis.

\section{INTRODUCTION}

Radiographic cephalometry is a vital tool for clinical and research orthodontics. ${ }^{1}$ Since its introduction by Broadbent $^{2}$ in 1931, numerous cephalometric analyses have been described over the years. These analyses are frequently used by orthodontists and maxillofacial surgeons for diagnosis, treatment planning, growth analysis and evaluation of treatment results. ${ }^{3}$

The McNamara ${ }^{4}$ analysis is a popular example, composed of eight linear and three angular measurements. The analysis provided a method that is simultaneously sensitive not only to the position of the teeth within a given jaw bone but also to the relationship of the two jaws, as well as the relationship between the jaws and cranial base. ${ }^{4}$ The relative positions of the maxilla and mandible, maxillary and mandibular lengths, the height of the face and the position of the incisors are described. It was developed for conventional orthodontic patients as well as for those with skeletal discrepancies requiring orthognathic surgery or growth modification. ${ }^{5}$

Studies have established McNamara norms for various population groups, the data having been found to vary amongst different age, racial and ethnic groups. ${ }^{6-11}$ Whilst Barter et al. ${ }^{12}$ established norms for Black South African children aged between 11 and 16 years, no McNamara norms for Black adults are available in the literature. This study seeks to determine these values for an adult Black South African sample.

\section{MATERIAL AND METHODS}

The study was approved by the Medunsa Research and Ethics Committee (MREC) of the University of Limpopo, Medunsa Campus, South Africa (Project number: MREC/ $D / 213 / 2012)$. The study material consisted of lateral cephalograms and study models of untreated Black adult subjects retrieved from the archives in the Department of Orthodontics, University of Limpopo, Medunsa Campus.

A total of 30 lateral cephalograms and study models (12 men and 18 women) were selected for this study. The criteria for selection were the following: Skeletal 
Class I; acceptable soft tissue profile ${ }^{12}$; Dental Class I; normal overjet and overbite; no severe crowding; no crossbites; no missing teeth except the third molars; and, no history of orthodontic treatment or orthognathic surgery.

All radiographs had been taken with the Frankfort horizontal plane parallel to the floor, the teeth in centric occlusion and the lips at rest. The analog cephalograms were taken with the Siemens, Orthopantomogram 10尺 while the digital radiographs were obtained using the Kodak $8000 C \circledast$ X-ray machine. The analog cephalograms were digitized using Vidar Sierra Advantage $®$ $X$-ray film digitizer. A ruler from the Dolphin software programme was attached to each cephalogram during the digitization process (Figure 1). The calibrations on the ruler served as a reference to enable adjustment for magnification of the image. ${ }^{8}$
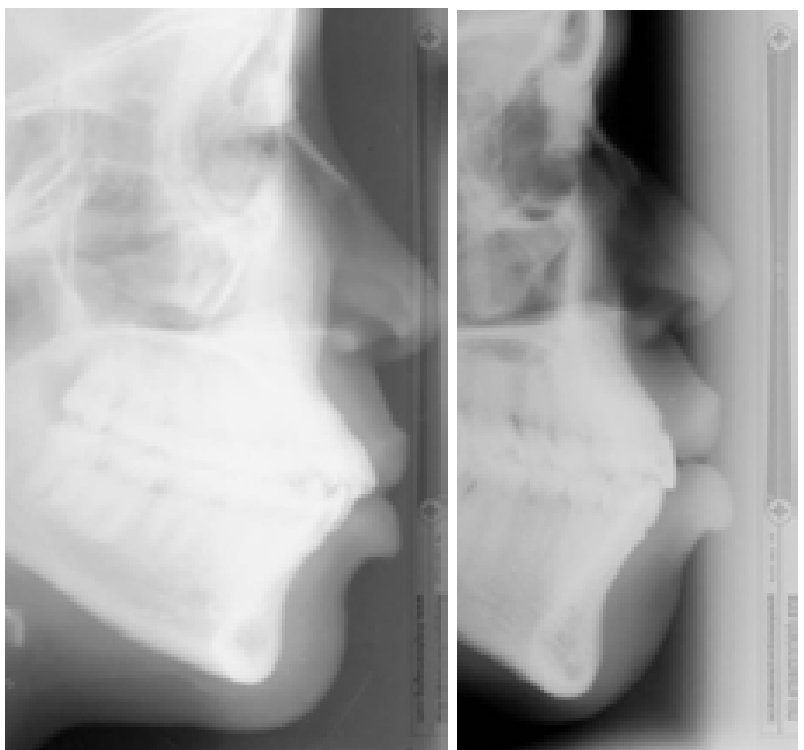

Figure 1: Digitized analog lateral cephalogram with a Dolphin ruler in place.

Dolphin Imaging 11.5 Premium $®$ cephalometric analysis computer software was used to trace and analyze the cephalograms. The landmarks and measurements for assessing skeletal classification and soft tissue profile are shown in Figure 2, and those for the McNamara ${ }^{4}$ (1984) analysis are illustrated in Figure 3. All measured variables of the McNamara analysis are shown in Table 1.

To determine the errors associated with landmark identification and measurements, five radiographs were randomly selected, retraced and re-measured by the principal investigator (intra-examiner reliability/error), as well as by the supervisor (inter-examiner reliability) two weeks after the initial measurements. The Pearson Correlation coefficient test was performed to determine intra- and inter-examiner reliability. Arithmetical means and standard deviation were calculated for all variables. A Shapiro-Wilk test was carried out to objectively assess the normality of distribution of the measured variables.

The mean values obtained from the sample for all the variables were compared with the $\mathrm{McNamara}^{4}$ norms (Ann Arbor sample) by a one-sample $t$ test. The mean values for male and female subjects were compared by a two-sample $t$ test. The level of significance was set

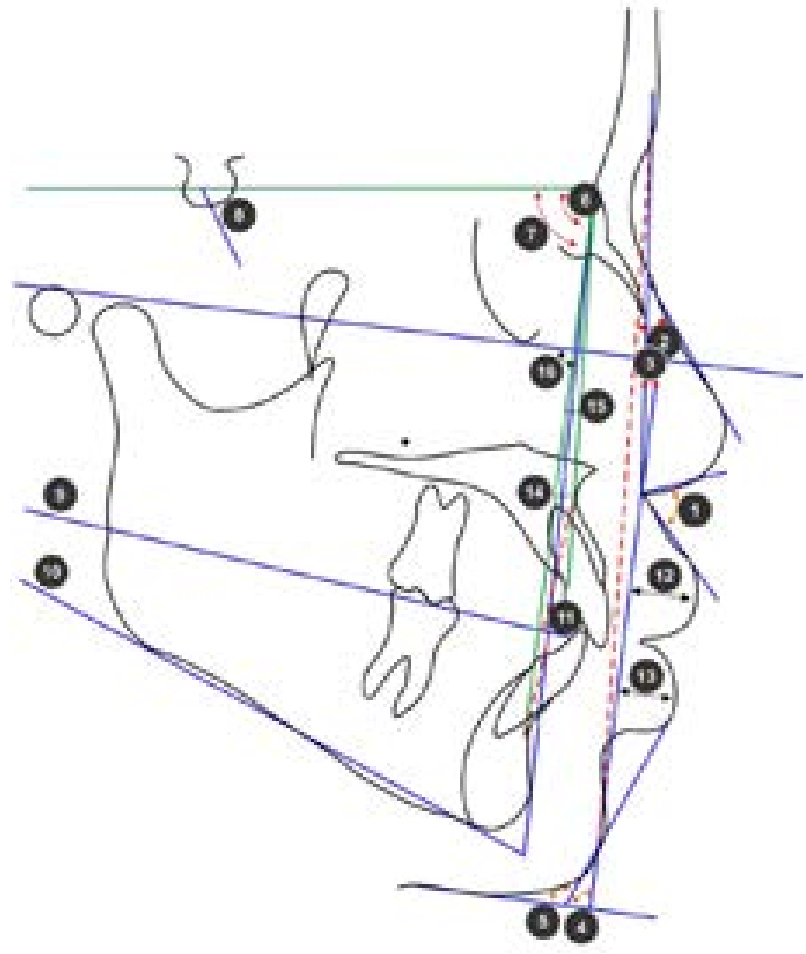

Figure 2: Linear and angular measurements to verify that a patient had skeletal Class I pattern and acceptable soft tissue profile 1) nasolabial angle, 2) nasofacial angle, 3) facial contour angle, 4) lower face-throat angle, 5) lower lip-chin-throat angle, 6) SNB, 7) SNA, 8) Y-axis, 9) occlusal plane, 10) mandibular plane angle, 11) Wits, 12) B-line upper lip, 13) B-line lower lip, 14) convexity, 15) ANB 16) face-plane.

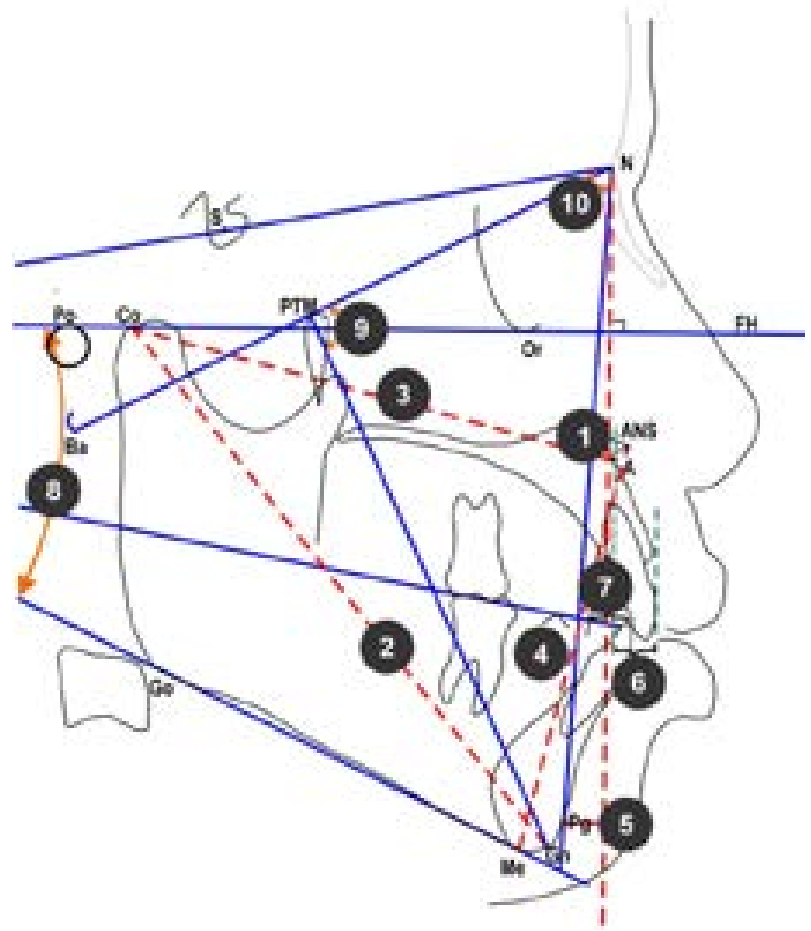

Figure 2: Landmarks, linear and angular measurements used for McNamara (1984) analysis 1) Distance from Point A to nasion perpendicular line, 2) Distance from condylion to gnathion, 3) Distance from condylion to Point A, 4) Distance from anterior nasal spine to menton, 5) Distance from point pogonion to the nasion perpendicular, 6) Distance from labial surface of upper incisor to Point A vertical, 7) Distance from tip of lower incisor to A-Pogonion line, 8) Angle between FH plane and Go-Me line, 9) Angle formed by intersection of N-Ba and PTM-Gn lines, 10) Angle formed by intersection of $\mathrm{SN}$ and $\mathrm{NA}$ lines. 
at $p \leq 0.05$. All statistical analyses were performed under the advice of a statistician and were processed using the Statistical Analysis System (SAS) 9.2 computer software programme.

\begin{tabular}{|c|c|}
\hline Measurements & Definition \\
\hline \multicolumn{2}{|l|}{ Maxilla to cranial base } \\
\hline $\begin{array}{l}\text { Nasion perpendicular to } \\
\text { point } A(\mathrm{~mm})\end{array}$ & $\begin{array}{l}\text { Distance from Point A to nasion } \\
\text { perpendicular line }\end{array}$ \\
\hline SNA angle & $\begin{array}{l}\text { Angle formed by intersection of SN } \\
\text { and NA lines }\end{array}$ \\
\hline \multicolumn{2}{|l|}{ Mandible to maxilla } \\
\hline $\begin{array}{l}\text { Effective mandibular } \\
\text { length }(\mathrm{mm})\end{array}$ & Distance from condylion to gnathion \\
\hline $\begin{array}{l}\text { Effective midfacial } \\
\text { length }(\mathrm{mm})\end{array}$ & Distance from condylion to Point $\mathrm{A}$ \\
\hline $\begin{array}{l}\text { Maxillomandibular } \\
\text { differential }(\mathrm{mm})\end{array}$ & $\begin{array}{l}\text { Midfacial length subtracted from } \\
\text { mandibular length }\end{array}$ \\
\hline $\begin{array}{l}\text { Lower anterior facial } \\
\text { height }(\mathrm{mm})\end{array}$ & $\begin{array}{l}\text { Distance from anterior nasal spine to } \\
\text { menton }\end{array}$ \\
\hline Mandibular plane angle & Angle between FH plane and Go-Me line \\
\hline Facial axis angle & $\begin{array}{l}\text { Angle formed by intersection of N-Ba and } \\
\text { PTM-Gn lines }\end{array}$ \\
\hline \multicolumn{2}{|l|}{ Mandible to cranial base } \\
\hline $\begin{array}{l}\text { Pogonion to nasion per- } \\
\text { pendicular }(\mathrm{mm})\end{array}$ & $\begin{array}{l}\text { Distance from point pogonion to the } \\
\text { nasion perpendicular }\end{array}$ \\
\hline \multicolumn{2}{|l|}{ Dentition } \\
\hline $\begin{array}{l}\text { Upper incisors to point A } \\
\text { vertical }(\mathrm{mm})\end{array}$ & $\begin{array}{l}\text { Distance from labial surface of upper } \\
\text { incisor to Point A vertical }\end{array}$ \\
\hline $\begin{array}{l}\text { Lower incisors to A-Po } \\
\text { line }(\mathrm{mm})\end{array}$ & $\begin{array}{l}\text { Distance from tip of lower incisor to } \\
\text { A-Pogonion line }\end{array}$ \\
\hline
\end{tabular}

\section{RESULTS}

The sample demographics are illustrated in Table 2.

There was no statistically significant difference between the ages of male and female subjects. The Shapiro-Wilk test revealed that more than $90 \%$ of the variables were normally distributed $(p>0.05)$. The intra- and inter-examiner reliability tests showed the correlation coefficient exceeded 0.8 indicating that the method of measurement was reliable and reproducible.

\section{Gender differences in the study sample}

Table 3 shows a comparison of the measured variables between male and female subjects. The mean values for four linear measurements (effective mandibular length; effective mid-facial length; maxillomandibular differential; and anterior lower facial height) were significantly larger in males than in females. The other four linear measurements (nasion perpendicular to Point A; pogonion to nasion perpendicular; upper incisor to Point A vertical; and lower incisors to A-Po line) and three angular measurements (SNA; mandibular plane; facial axis angle) showed no statistically significant difference between male and female subjects.

\section{Comparison between study and Ann Arbor} male sample

Table 4 shows a comparison of the measured variables between the study and the Ann Arbor male sample. The mean values for two linear measurements (upper

\begin{tabular}{|c|c|c|c|c|c|c|c|}
\hline Sample (n) & Number & $\begin{array}{c}\text { Mean age } \\
\text { (years) }\end{array}$ & SD & Median & Minimum & Maximum & p-value \\
\hline Males & 12 & 25.1 & 5.09 & 24.0 & 20 & 39 & \multirow[b]{2}{*}{0.294} \\
\hline Females & 18 & 23.3 & 2.81 & 23.0 & 20 & 29 & \\
\hline Total & 30 & 24 & 3.90 & 23.5 & 20 & 39 & \\
\hline
\end{tabular}

\begin{tabular}{|c|c|c|c|c|c|c|}
\hline Parameters & $\begin{array}{l}\text { Male } \\
\text { Mean }\end{array}$ & $\begin{array}{l}\text { Female } \\
\text { Mean }\end{array}$ & $\begin{array}{c}\text { Mean } \\
\text { difference }\end{array}$ & t-value & $p$-value & $\begin{array}{c}95 \% \mathrm{Cl} \\
\text { for mean } \\
\text { difference }\end{array}$ \\
\hline \multicolumn{7}{|l|}{ Maxilla to cranial base } \\
\hline Nasion perpendicular to point $\mathrm{A}(\mathrm{mm})$ & 1.32 & 3.84 & 2.53 & 1.89 & 0.0693 & $-0.214-5.269$ \\
\hline SNA angle $\left({ }^{\circ}\right)$ & 83.23 & 85.81 & 2.58 & 1.81 & 0.0807 & $-0.336-5.492$ \\
\hline \multicolumn{7}{|l|}{ Mandible to maxilla } \\
\hline Effective mandibular length (mm) & 129.63 & 123.50 & 6.13 & -3.50 & 0.0016 & $-9.717--2.542$ \\
\hline Effective midfacial length (mm) & 98.51 & 95.53 & 2.98 & -2.55 & 0.0164 & $-5.379--0.591$ \\
\hline Maxillomandibular differential (mm) & 31.12 & 28.03 & 3.09 & -2.97 & 0.0060 & $-5.219--0.959$ \\
\hline Lower anterior facial height (mm) & 77.08 & 73.65 & 3.43 & -2.05 & 0.0499 & $-6.855--0.001$ \\
\hline Mandibular plane angle $\left({ }^{\circ}\right)$ & 22.60 & 23.43 & 0.83 & 0.69 & 0.4981 & $-1.651-3.315$ \\
\hline Facial axis angle $\left({ }^{\circ}\right)$ & -1.45 & 0.27 & 1.73 & 1.60 & 0.1209 & $-0.485-3.937$ \\
\hline \multicolumn{7}{|l|}{ Mandible to cranial base } \\
\hline Pogonion to nasion perpendicular (mm) & -3.43 & -0.77 & 2.67 & 1.14 & 0.2650 & $-2.136-7.469$ \\
\hline \multicolumn{7}{|l|}{ Dentition } \\
\hline Upper incisors to point A vertical (mm) & 8.45 & 9.59 & 1.15 & 1.65 & 0.1107 & $-0.279-2.571$ \\
\hline Lower incisors to A-Po line (mm) & 6.47 & 7.26 & 0.79 & 1.08 & 0.2893 & $-0.707-2.285$ \\
\hline
\end{tabular}


incisors to point A vertical and lower incisors to A-Po line) were significantly larger in the study than for those of the Ann Arbor male sample.

The mean value for one angular measurement (facial axis angle) was found to be significantly smaller in the study sample than in the Ann Arbor sample. The mean values for the other six linear measurements (nasion perpendicular to point A; effective mandibular length; effective midfacial length; maxillomandibular differential; lower anterior facial height; and, pogonion to nasion perpendicular) and two angular measurements (SNA and mandibular plane angle) were not statistically significant.

\section{Comparison between study and Ann Arbor female sample}

Table 5 shows the comparison of the measured variables between the study sample and Ann Arbor female sample.
The mean values for six linear measurements (nasion perpendicular to Point $A$; effective mandibular length; effective midfacial length; lower anterior facial height; upper incisors to Point A vertical; and, lower incisors to A-Po line) and one angular (SNA angle) measurement were significantly larger in the study sample than in the Ann Arbor females. The mean values for the other two linear measurements (maxillomandibular differential and pogonion to nasion perpendicular) and two angular measurements (facial axis and mandibular plane angles) were not statistically significant.

\section{DISCUSSION}

This study set out to establish McNamara norms for a population of adult Black South Africans, compare that data with Ann Arbor population norms, and examine for gender differences in the measurements.

\begin{tabular}{|c|c|c|c|c|c|}
\hline \multirow[t]{2}{*}{ Parameters } & \multicolumn{3}{|c|}{$\begin{array}{l}\text { Study sample } \\
\qquad(n=12)\end{array}$} & \multirow{2}{*}{$\begin{array}{c}\text { Ann Arbor sample } \\
\begin{array}{c}(\mathbf{n}=38) \\
\text { Mean }\end{array}\end{array}$} & \multirow[t]{2}{*}{$p$-values } \\
\hline & Mean & t-value & $95 \% \mathrm{Cl}$ of mean & & \\
\hline \multicolumn{6}{|l|}{ Maxilla to cranial base } \\
\hline Nasion perpendicular to point A $(\mathrm{mm})$ & 1.32 & 1.89 & $-1.02-3.65$ & 1.1 & 0.8419 \\
\hline SNA angle $\left({ }^{\circ}\right)$ & 83.2 & 1.81 & $80.55-85.92$ & 83.9 & 0.5957 \\
\hline \multicolumn{6}{|l|}{ Mandible to maxilla } \\
\hline Effective mandibular length $(\mathrm{mm})$ & 129.6 & -3.50 & $126.2-133.1$ & 132.3 & 0.1172 \\
\hline Effective midfacial length (mm) & 98.5 & -2.55 & $96.47-100.6$ & 99.8 & 0.1934 \\
\hline Maxillomandibular differential (mm) & 31.1 & -2.97 & $29.12-33.12$ & 32.5 & 0.1561 \\
\hline Lower anterior facial height (mm) & 77.1 & -2.05 & $73.68-80.47$ & 74.6 & 0.1367 \\
\hline Mandibular plane angle $\left({ }^{\circ}\right)$ & 22.6 & 0.69 & $20.56-24.63$ & 21.3 & 0.1888 \\
\hline Facial axis angle $\left({ }^{\circ}\right)$ & -1.5 & 1.60 & $-3.17-0.26$ & 0.5 & 0.0290 \\
\hline \multicolumn{6}{|l|}{ Mandible to cranial base } \\
\hline Pogonion to nasion perpendicular (mm) & -3.4 & 1.14 & $-7.16-0.29$ & -0.3 & 0.091 \\
\hline \multicolumn{6}{|l|}{ Dentition } \\
\hline Upper incisors to point A vertical $(\mathrm{mm})$ & 8.5 & 1.65 & $7.06-9.83$ & 5.3 & 0.0004 \\
\hline Lower incisors to A-Po line (mm) & 6.5 & 1.08 & $4.94-7.99$ & 2.3 & 0.0001 \\
\hline
\end{tabular}

\begin{tabular}{|c|c|c|c|c|c|}
\hline \multirow[t]{2}{*}{ Parameters } & \multicolumn{3}{|c|}{$\begin{array}{l}\text { Study sample } \\
\qquad(n=18)\end{array}$} & \multirow{2}{*}{$\begin{array}{l}\text { Ann Arbor sample } \\
\begin{array}{c}(\mathbf{n}=\mathbf{3 8}) \\
\text { Mean }\end{array}\end{array}$} & \multirow[t]{2}{*}{$p$-values } \\
\hline & Mean & t-value & $95 \% \mathrm{Cl}$ of mean & & \\
\hline \multicolumn{6}{|l|}{ Maxilla to cranial base } \\
\hline Nasion perpendicular to point $\mathrm{A}(\mathrm{mm})$ & 3.84 & 1.89 & $2.09-5.60$ & 0.4 & 0.0007 \\
\hline SNA angle $\left({ }^{\circ}\right)$ & 85.8 & 1.81 & $84.06-87.56$ & 82.4 & 0.0007 \\
\hline \multicolumn{6}{|l|}{ Mandible to maxilla } \\
\hline Effective mandibular length (mm) & 123.5 & -3.50 & $121.4-125.6$ & 120.2 & 0.0036 \\
\hline Effective midfacial length (mm) & 95.5 & -2.55 & $94.00-97.06$ & 91.0 & 0.0001 \\
\hline Maxillomandibular differential (mm) & 28.0 & -2.97 & $26.77-29.29$ & 29.2 & 0.0661 \\
\hline Lower anterior facial height (mm) & 73.7 & -2.05 & $71.74-75.56$ & 66.7 & 0.0001 \\
\hline Mandibular plane angle $\left({ }^{\circ}\right)$ & 23.4 & 0.69 & $21.80-25.06$ & 22.7 & 0.3602 \\
\hline Facial axis angle $\left({ }^{\circ}\right)$ & 0.3 & 1.60 & $-1.23-1.77$ & 0.2 & 0.9203 \\
\hline \multicolumn{6}{|l|}{ Mandible to cranial base } \\
\hline Pogonion to nasion perpendicular (mm) & -0.8 & 1.14 & $-4.03-2.49$ & -1.8 & 0.5126 \\
\hline \multicolumn{6}{|l|}{ Dentition } \\
\hline Upper incisors to point A vertical $(\mathrm{mm})$ & 9.6 & 1.65 & $8.78-10.40$ & 5.4 & 0.0001 \\
\hline Lower incisors to A-Po line (mm) & 7.3 & 1.08 & $6.46-8.05$ & 2.7 & 0.0001 \\
\hline
\end{tabular}


Four linear measurements relating maxilla to the mandible demonstrated a statistically significant difference between the male and female sample. The effective mandibular length, effective mid-facial length, maxillomandibular differential and lower anterior facial height values in males were significantly larger than in females. These findings were in agreement with several other studies. $4,6-8,10,11$

These findings are an indication that male subjects have larger mandibular and maxillary skeletal structures than females. This finding could be related to the well-known time differences in craniofacial growth; male subjects grow for a longer period of time and therefore have larger maxillary and mandibular skeletal structures than females. ${ }^{13-15}$

No statistically significant difference was found in the two angular measurements for vertical dimension, linear measurement for the position of the mandible and linear measurement of the positions of the upper and lower incisors. However, the female sample demonstrated a more vertical tendency as measured by the mandibular plane angle, a more protrusive mandibular position and more protrusive upper and lower incisor positions. These findings are similar to data previously reported with regard to the vertical dimension, ,4,6,8,10 the mandibular position, ${ }^{8}$ and the upper ${ }^{4,6}$ and $l o w e r^{4,6}$ incisors position.

\section{Comparison between study sample and Ann Arbor male sample}

Only three variables (facial axis angle; upper incisor to Point A vertical; lower incisor to APO line) were found to be significantly different between the current study and the Ann Arbor sample. The facial axis angle in the present study sample was smaller (more negative, i.e. $-1.5^{\circ}$ versus $0.5^{\circ}$ ) than that of the Ann Arbor sample. The mean value of upper incisors to Point $A$ vertical in this study was $3.2 \mathrm{~mm}$ larger compared with the Ann Arbor male sample. The lower incisor to APO measurement was $4.2 \mathrm{~mm}$ greater than the McNamara norms.
These findings were in agreement with those of a number of researchers for both upper and lower incisor positions. ${ }^{6-8,10}$ Furthermore, the findings in this study concur with those of other studies with regards to the facial axis angle..$^{6,11}$

The other eight variables showed no statistically significant differences between the two groups. However, the mean values for the effective mandibular length, effective maxillary length and pogonion to nasion perpendicular were larger in the Ann Arbor male sample. On the contrary, the mean values of the nasion perpendicular to point $A$ and mandibular plane angle were larger in the Black male sample. Similar findings have been reported for effective mandibular and maxillary lengths. ${ }^{6,7,10,11}$ Additionally, larger lower anterior facial height values have also been found. ${ }^{6,8,10}$

The results of the current study suggest that Black subjects have protrusive upper and lower incisors (bimaxillary protrusion) as well as an increased lower anterior facial height. A combination of increased lower facial height with relatively shorter maxilla and mandible (a finding in the current study although not statistically significant) further suggests that Black subjects of the present study have a tendency to downward and backward rotation of the mandible and a convex facial profile compared with Caucasians.

\section{Comparison between study sample and Ann Arbor female sample}

A comparison of the female results showed that the values of seven (7) out of eleven (11) variables were statistically significantly larger in the present study compared with the McNamara norms. These variables are: SNA angle; nasion perpendicular to point $A$; effective mandibular length; effective maxillary length; lower anterior facial height; upper incisors to point A; and lower incisors to APO. Except for the Saudis ${ }^{8}$ mandibular and maxillary lengths, the values from the present study revealed larger figures than any reported previously (Table 6).

\begin{tabular}{|c|c|c|c|c|c|c|c|c|c|c|c|c|c|c|}
\hline Authors & \multirow{2}{*}{\multicolumn{2}{|c|}{$\begin{array}{c}\text { McNamara } \\
1984\end{array}$}} & \multicolumn{2}{|c|}{$\begin{array}{l}\text { Miyajima } \\
\text { et al. }\end{array}$} & \multirow{2}{*}{\multicolumn{2}{|c|}{$\begin{array}{c}\text { Basciftci } \\
\text { et al. } \\
2004\end{array}$}} & \multirow{2}{*}{\multicolumn{2}{|c|}{$\begin{array}{c}\text { Al-Barakati } \\
\text { and Talic } \\
2007\end{array}$}} & \multirow{2}{*}{\multicolumn{2}{|c|}{ Nahidh }} & \multicolumn{2}{|c|}{$\begin{array}{l}\text { Gu } \\
\text { et al. }\end{array}$} & \multicolumn{2}{|c|}{$\begin{array}{l}\text { Present } \\
\text { study }\end{array}$} \\
\hline Year & & & & 996 & & & & & & & & 11 & & 14 \\
\hline Country & \multicolumn{2}{|c|}{ USA } & \multicolumn{2}{|c|}{ Japan } & \multicolumn{2}{|c|}{ Turkey } & \multicolumn{2}{|c|}{ Saudi Arabia } & \multicolumn{2}{|c|}{ Iraq } & \multicolumn{2}{|c|}{ China } & \multicolumn{2}{|c|}{ South Africa } \\
\hline Gender & Male & Female & Male & Female & Male & Female & Male & Female & Male & Female & Male & Female & Male & Female \\
\hline Sample & 38 & 73 & 26 & 28 & 50 & 55 & 36 & 29 & 33 & 42 & 25 & 40 & 12 & 18 \\
\hline NP-A (mm) & 1.1 & 0.4 & 2.5 & 2.3 & 0.7 & 0.2 & -2.0 & -0.2 & 1.6 & 0.7 & 1.0 & 0.0 & 1.3 & 3.8 \\
\hline SNA $\left({ }^{\circ}\right)$ & 83.9 & 82.4 & 82.2 & 82.1 & 83.3 & 81.9 & - & - & 83.8 & 81.8 & 85.1 & 83.6 & 83.2 & 85.8 \\
\hline Co-Gn(mm) & $\begin{array}{c}134.3 \\
{[132.3]^{\star}}\end{array}$ & 120.2 & 125.5 & 118.8 & 126.4 & 117.8 & 133.4 & 124.9 & 121.4 & 111.0 & 125.4 & 119.4 & 129.6 & 123.5 \\
\hline Co-A (mm) & 99.8 & 91.0 & 91.4 & 86.3 & 95.1 & 90.4 & 101.7 & 98.2 & 93.2 & 85.5 & 92.0 & 87.5 & 98.5 & 95.5 \\
\hline MM diff (mm) & $\begin{array}{c}34.5 \\
{[32.5]^{\star \star}}\end{array}$ & 29.2 & 34.1 & 32.5 & 31.3 & 27.4 & 31.8 & 26.8 & 28.2 & 25.7 & 33.4 & 31.9 & 31.1 & 28.0 \\
\hline LAFH (mm) & 74.6 & 66.7 & 75.1 & 72.7 & 75.1 & 68.3 & 76.1 & 68.9 & 68.8 & 63.4 & 74.9 & 69.4 & 77.1 & 73.7 \\
\hline FMPA $\left({ }^{\circ}\right)$ & 21.3 & 22.7 & 22.3 & 26.1 & - & - & 24.9 & 25 & 21.7 & 23.9 & - & - & 22.6 & 23.4 \\
\hline FAA $\left({ }^{\circ}\right)$ & 0.5 & 0.2 & -4.2 & -3.5 & -1.3 & -1.0 & 2.8 & 2.9 & -0.6 & -0.2 & -5.4 & -2.2 & -1.5 & 0.3 \\
\hline Pog-NP (mm) & -0.3 & -1.8 & 0.3 & -1.7 & -1.5 & -1.8 & -6.1 & -5.9 & -0.1 & -1.4 & -3.2 & -6.6 & -3.4 & -0.8 \\
\hline UI-PA Vert (mm) & 5.3 & 5.4 & 5.7 & 6 & - & - & 6.2 & 4.3 & 6.4 & 5.9 & 5.2 & 4.5 & 8.5 & 9.6 \\
\hline LI-A-Pog (mm) & 2.3 & 2.7 & 4 & 4.9 & 2.6 & 2.3 & 4.4 & 3.6 & 4.0 & 4.0 & 4.1 & 4.1 & 6.5 & 7.3 \\
\hline
\end{tabular}


The current findings with regard to the position of maxilla differ from the results of other studies that found the SNA to be smaller than that of the McNamara norms. ${ }^{6,7,10}$ Similar results of smaller mean values of point $A$ to nasion perpendicular were reported in two studies. ${ }^{8,11}$

A similar trend of smaller values than the McNamara norms was found with regard to effective mandibular and maxillary lengths. ${ }^{6,7,10,11}$ By contrast, several studies reported greater values than the McNamara norms for the lower anterior facial height, ${ }^{6-8,11}$ upper incisor to point $A$ vertical ${ }^{6,10}$ and lower incisors to APO. $6,8,10,11$

The interpretation of the current findings suggests that the Black female subjects had prognathic maxillae (larger SNA and nasion perpendicular to point A), larger mandibles (effective mandibular length) and maxillae (effective maxillary length), longer lower anterior facial height and procumbent upper (upper incisors to point A vertical) and lower incisors (lower incisors to APO). In addition, the mandible was also protrusive, even though the values were not statistically significant.

These findings further suggest that a combination of larger maxilla, protrusive maxilla and maxillary incisors together with larger mandible, protrusive mandible and mandibular incisors (bimaxillary skeletal and dental protrusion) is a characteristic feature of the current female study subjects.

Bimaxillary protrusion has been established as a common feature among the general Black population as well as among Black South African subjects. ${ }^{16-20}$ Our study sample subjects, therefore, appear to have facial features shared with other Black individuals from other parts of the world.

\section{Limitation of the study}

The sample size in this study was small. However, it was representative of the target population. A large number of significance tests were also carried out on the data. These two factors increase the possibility of making type I and || errors.

\section{CONCLUSION}

Within the limitations of the current study, the following conclusions can be drawn:

- There are significant gender differences in the study sample, with male subjects having significantly larger mandibles, maxillae and lower anterior facial height structures.

- The present male study subjects demonstrated a significantly smaller facial axis angle, and significantly more procumbent upper and lower incisors compared with the Ann Arbor sample.

- The females from this study were found to have significantly larger and protrusive maxillae, significantly larger but non-significantly protrusive mandibles, significantly greater lower anterior facial heights, and significantly procumbent upper and lower incisors compared with the Caucasian Ann Arbor sample.
- The Ann Arbor (McNamara) norms may be applicable to the male study sample except for the facial axis angle, upper incisors to Point $A$ vertical and lower incisors to A-Po line measurement. The Ann Arbor norms are, however, not applicable to the female study sample.

- A more comprehensive survey including a larger sample drawn from a wider population is indicated to confirm the results of this study.

\section{References}

1. Viteporn S. The technique of cephalometric radiography. In: Athanasiou AE, ed. Orthodontic Cephalometry. London: Mosby Wolfe, 1995: 9-20.

2. Broadbent $\mathrm{BH}$. A new X-ray technique and its application to orthodontia. Angle Orthod. 1931;(1):45-66.

3. McNamara JA, Brudon WL. Cephalometric evaluation In: Orthodontics and Dentofacial Orthopedics. Ann Arbor, Michigan, Needham Press, 2001: 487-517.

4. McNamara JA. A method of cephalometric evaluation. Am J Orthod. 1984;86(6):449-69.

5. Wu J, Hagg U, Rabie ABM. Chinese norms of McNamara's cephalometric analysis. Angle Orthod 2007;77(1):12-20.

6. Miyajima K, McNamara JA, Kimura T, Murata S, Lizuka T. Craniofacial structure of Japanese and European-American adults with normal occlusions and well-balanced faces. Am J Orthod Dentofacial Orthop. 1996;110(4):431-8.

7. Basciftci FA, Uysal T, Buyukerkmen A. Craniofacial structure of Anatolian Turkish adults with normal occlusions and well-balanced faces. Am J Orthod Dentofacial Orthop. 2004; 125(3):366-72.

8. Al-Barakati SF, Talic NF. Cephalometric norms for Saudi sample using McNamara analysis. Saudi Dent J. 2007;19(3):139-45.

9. Kilic N, Catal G, Oktay H. McNamara norms for Turkish adolescents with balanced faces and normal occlusion. Aust Orthod J. 2010;26(1):33-7.

10. Nahidh M. Iraqi cephalometric norms using McNamara analysis. Journal of Baghdad College of Dentistry. 2010;22(3):123-7.

11. Gu Y, McNamara Jr JA, Sigler LM, Baccetti T. Comparison of craniofacial characteristics of typical Chinese and Caucasian young adults. Eur J Orthod. 2011;33(2):205-11.

12. Barter MA, Evans WG, Smit GL, Becker PJ. Cephalometric analysis of a Sotho-Tswana group. J Dent Assoc S Afr. 1995;50(11):539-44.

13. Miklashevskaya NN. Sex differences in growth of the head and face in children and adolescents. Human Biology 1969;41(2):250-62.

14. Farkas LG, Posnick JC. Growth and development of regional units in the head and face based on anthropometric measurements. Cleft Palate Craniofac J. 1992;29(4):301-2.

15. Proffit WR. Later stages of development. In: Proffit WR, Fields HW, Sarver DM, Acerman JL, eds. Contemporary Orthodontics. St Louis, Missouri: Elsevier Mosby, 2013: 92-113.

16. Isiekwe, M. A cephalometric study of incisor angulations in a Nigerian population. J Orthod. 1989;16(3):177-81.

17. Farrow AL, Zarrinnia K, Azizi K. Bimaxillary protrusion in black Americans: an esthetic evaluation and treatment considerations. Am J Orthod Dentofacial Orthop. 1993;104(3):240-50.

18. Carter NE, Slattery, DA. Bimaxillary proclination in patients of Afro-Caribbean origin. J Orthod Sci. 1998;15(3):175-84.

19. Dandajena TC, Nanda RS. Bialveolar protrusion in a Zimbabwean sample. Am J Orthod Dentofacial Orthop. 2003;123(2):133-7.

20. Beukes S, Dawjee SM, Hlongwa P. Facial profile perceptions in a group of South African Blacks. S Afr Dent J. 2007;62(4):160-7. 